\title{
Tricaine methane-sulfonate (MS-222) application in fish anaesthesia
}

\author{
By N. Topic Popovic ${ }^{1}$, I. Strunjak-Perovic ${ }^{1}$, R. Coz-Rakovac ${ }^{1}$, J. Barisic ${ }^{1}$, M. Jadan ${ }^{1}$, A. Persin Berakovic ${ }^{2}$ \\ and R. Sauerborn Klobucar ${ }^{1}$ \\ ${ }^{1}$ Laboratory for Ichthyopathology - Biological Materials, Division for Materials Chemistry, Rudjer Boskovic Institute, Zagreb,
Croatia; ${ }^{2}$ Department of Anaesthesiology, University Hospital Clinic, Zagreb, Croatia
}

\begin{abstract}
Summary
Tricaine methane-sulfonate (MS-222) is one of the most widely used anaesthetics for poikilotherms worldwide. This paper outlines its anaesthetic efficacy and dosage in fish and legislation for its use, fish stress responses to MS-222 anaesthesia and its effect on fish physiology and blood properties, pharmacokinetics, genotoxicity, immune response, potential interference with fish hepatic cytochrome P450 spectra, and its impact on nerve sensitivity. Key questions arising from the available data are analysed, such as regulatory constraints on its use, the need for the standardization of buffering protocols, and interdependencies of the factors impacting the specific applicative efficacy of MS-222. Current research has provided an abundance of data on MS-222 use in fish, although the applications within these studies are often impractical at the farming level. Specific emphasis is therefore placed on highlighting application strategies on a practical basis, presenting potential future research on topics that require in-depth analysis (preparation and storage of anaesthetic solutions, pre-anaesthetic sedation and stress reduction, cortisol response in aquarium fish, toxicity of MS-222 metabolites, and possible immunodepressive properties). Additionally, both from a scientific and practical perspective, it is necessary to have a better understanding of safety margins, induction, immersion and recovery times for many (marine and freshwater, farmed and ornamental) fish species in order to achieve optimal utilization.
\end{abstract}

\section{Introduction}

Anaesthesia, euthanasia and sedation of fish, both wild and captive, are common practices and requirements in aquaculture and experimental procedures. Tricaine methane-sulphonate (MS-222), $\mathrm{C}_{9} \mathrm{H}_{11} \mathrm{O}_{2} \mathrm{~N}+\mathrm{CH}_{3} \mathrm{SO}_{3} \mathrm{H}$, also known as ethyl $\mathrm{m}$-amino benzoate, tricaine mesilate, $\mathrm{m}$-aminobenzoic acid ethyl ester methanesulfonate and metacaine, has been one of the most widely used anaesthetic agents for poikilotherms worldwide since its introduction in 1967 . It was originally produced as a local analgesic alternative to cocaine and has been used as such in humans. However, its value as an anaesthetic for aquatic animals was soon recognized and its further development was exclusively for this purpose. Supplied as a white crystalline powder as a $100 \%$ pure drug, it is intended for dissolution in water; one advantage is a solubility to $11 \%$, forming a clear colourless acid solution. A very high lipid solubility makes it suitable for use in both freshwater and seawater (Brown, 1993; EMEA, 1999; Treves-Brown, 2000; Ortuno et al., 2002; Coyle et al., 2004; Daniel, 2009; Maricchiolo and Genovese, 2011).
MS-222 is used for diverse routine operations such as the selection of fish, sorting, grading, weight/length measurements, sampling, labelling, transportation, broodstock anaesthesia, gamete collection, physiological data collection, blood sampling, health monitoring, vaccination, radio transmitter implanting and invasive surgery such as implantation of serial sampling devices (e.g. cannulas, catheters) for the collection of bile, blood and urine (Spaeth and Schweickert, 1977; Jennings and Looney, 1998; Redman et al., 1998; McKim et al., 1999; Tapper et al., 2000; Bowser, 2001; Wagner et al., 2003; Lewbart et al., 2005; Cotter and Rodnick, 2006; Kiessling et al., 2009; Weber et al., 2009; Brown et al., 2011). Intraarterial or tissue implantation of microdialysis probes also requires the use of MS-222. Fish have been anaesthetised prior to liver perfusion for the preparation of isolated hepatocytes (Kolanczyk et al., 2003). MS-222 is widely used with larval and ornamental fish to reduce transport stress, facilitate handling and sorting, immobilise larvae for force-feeding, study the role of muscular contraction in the development of various skeletal pathologies, limit activity in metabolic studies and for various surgical procedures (Guo et al., 1995; Massee et al., 1995; Rombough, 2007; Kucuk, 2010; Pramod et al., 2010). Aeration should be provided unless sedation or anaesthesia is of short duration. A controlled overdose is often used for humanely euthanizing fish prior to the lethal sampling of tissues or blood (Holloway et al., 2004; Sinclair, 2004; Wilson et al., 2009).

The aim of this paper is to present a critical review of MS222 application in fish, its efficacy and dosage, genotoxicity, impact on fish physiology and blood properties, immune response issues and fish stress responses, and to give an overview of recent literature reports and advances in the field of fish pharmacology. Emphasis has been placed on highlighting practical application strategies and potential future research. Given the importance of sedating fish within the context of fish welfare, there is a growing trend towards exploring the diverse aspects and proper use of MS-222, which has been compounded by the constraints of employing veterinary medicinal products in the aquaculture industry.

\section{Legal aspects}

In recent decades, European legislation regarding veterinary pharmaceuticals has introduced restrictions for use of medicines in treatment of farm animals; as a result, available veterinary medicinal products for fish are now authorised. The main document regarding the availability of aquaculture medicines is the regulation for the establishment of maximum

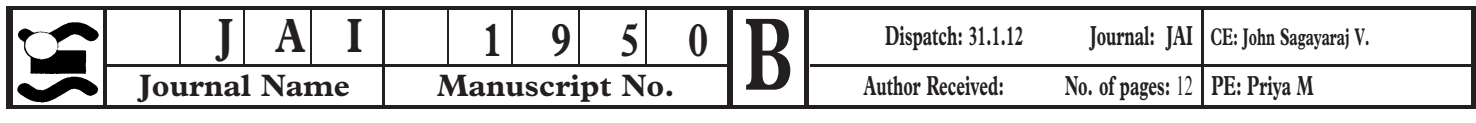


residue limits (MRL) (CEC, 1990). In its Annex II, MS-222 is authorised within the list of substances not subject to MRLs designated for finfish, for water-borne use only (CEC, 1990; EMEA, 1999). However, in many European countries there is no registered fish anaesthetic, and the list of pharmaceuticals licensed for fish varies. For example, MS-222 is not licensed in Spain, Greece or France, while it is permitted in the United Kingdom (UK), Italy, Spain and Norway (EFSA, 2008; Daniel, 2009). Some European countries have limitations regarding the use of MS-222, such as Italy, where it is approved only for vaccination and research purposes (EFSA, 2008). Countries exporting fish into the European Union (EU) are required to demonstrate that they comply with the respective EU regulations on the use and withdrawal of anaesthetics. Therefore, potential MS-222 users within Europe should consult their regional legislation prior to administration to fish. In the United States MS-222 is approved by the U.S. Food and Drug Administration for use as a fish anaesthetic, but only on Ictaluridae, Salmonidae, Esocidae and Percidae (FDA, 2006). The recommended withdrawal time of MS-222 varies among countries. For instance, the U.S.A. and Norway have a 21-day withdrawal period before the fish can be consumed. Canada requires a 5-day withdrawal period for water temperatures above $10^{\circ} \mathrm{C}$ (Wagner et al., 2002; Western Chemical, 2008; Kiessling et al., 2009; AFS, 2011), New Zealand 10 days (Ross and Ross, 2008), while in the UK fish are deemed fit for human consumption after 70 degree days prior to the last MS-222 application (Pharmaq, 2010). Although it is reported to be non-mutagenic (Yoshimura et al., 1981; EMEA, 1999; Alpharma, 2001), care should be taken regarding withdrawal if fish are intended for human consumption, since MS-222 is regarded as carcinogenic (Pirhonen and Schreck, 2003). MS-222 should be handled with caution, since it may cause skin and respiratory tract irritation (Sigma, 2007). It has also been reported to cause reversible retinal toxicity related to chronic occupational exposure, requiring protective clothing to avoid contact during use (Bernstein et al., 1997). The additional legislative matters affecting safety and methods of use are important and are growing. Therefore, MS-222 users are urged to follow through and adhere to all updated and necessary regulations for the location in which they operate.

\section{Buffering and storage}

Some studies suggest that MS-222 has a minimal effect on the water acidity (Alpharma, 2001), although many authors disagree. Therefore, it is prudent to consider buffering anaesthetic solutions, as MS-222 is typically acquired in acidic form that can yield a $\mathrm{pH}$ as low as 2.8 in water, depending on the water hardness and MS-222 concentration (Ohr, 1976). Acidity results from the formation of methanesulfonic acid (Smith et al., 1999). Under low $\mathrm{pH}$ conditions, disturbances in fish ionic and osmotic balance can lead to haemoconcentration, increased blood pressure and a suppressed metabolic rate (Packer, 1979; Milligan and Wood, 1982; Iwama et al., 1989; Burka et al., 1997; Pelster and Randall, 1998; Carter et al., 2011). Although unbuffered MS-222 is acidic in aqueous solutions, some authors dissolved it in ionized water or dechlorinated tank water (Xu et al., 2008; Zahl et al., 2009). $\mathrm{Xu}$ et al. (2008) investigated the effects of buffered and unbuffered MS-222 in dechlorinated tank water on the survival and reproduction of a fish ectoparasite. A constant $\mathrm{pH}$, between 7.25 and 7.38, was maintained in the buffered solution, whereas the $\mathrm{pH}$ of the unbuffered solution was significantly reduced. In a separate study Zahl et al. (2009) dissolved MS-222 in ionised water and added the solution to seawater tanks to evaluate anaesthesia on Atlantic cod (Gadus morhua). Due to the buffering capacity of seawater, MS-222 induced only a minor $\mathrm{pH}$ reduction from 7.9 to 7.5 . It would thus appear that unbuffered MS-222 solutions have higher safety margins in the seawater. Although saltwater and freshwater with higher alkalinities contain a sufficient buffering capacity to maintain an acceptable pH (Piper et al., 2001; Carter et al., 2011), buffering protocols should be standardised, both for experimental and practical farm purposes.

It is recommended that MS-222 be buffered with imidazole, sodium hydrogen phosphate or sodium hydroxide (Brown, 1993; Davis et al., 2008). The most commonly used buffer is sodium bicarbonate $\left(\mathrm{NaHCO}_{3}\right)$, as a 1:2 ratio solution in tank water (Kolanczyk et al., 2003; Pirhonen and Schreck, 2003; Wagner et al., 2003). Although there are literature reports on the use of $\mathrm{NaHCO}_{3}$ in distilled water (Barreto et al., 2007), the water used to anaesthetise fish should be taken from the environment (aquarium, sea cage, tank); distilled or deionized water should not be used, as neither possesses any buffering capacity (Smit et al., 1977). Bicarbonate-neutralized MS-222 at $\mathrm{pH}>7$ results in faster (shorter induction time), longer lasting and more consistent anaesthesia with reduced recovery times (Ohr, 1976; Smit and Hattingh, 1979), while the use of unbuffered MS-222 may cause serious epidermal and corneal damage in fish (Davis et al., 2008). The American Veterinary Medical Association (AVMA) recommends that only solutions at or exceeding $500 \mathrm{mg} / \mathrm{L}$ need to be buffered when euthanizing fish (AVMA, 2007).

Users of MS-222 are interested in methods of preparation and storage of solutions for easier handling. The reported shelflife of the substance after dilution or reconstitution varies from $12 \mathrm{~h}$ (Pharmaq, 2010), 3-10 days (Western Chemical, 2008), one month (Alpharma, 2001), and up to 3 months (Ross and Ross, 2008) if kept in a dark and cool place. The colour of MS-222 solutions may change rapidly to yellow or brown when exposed to light, which does not affect its activity. A $10 \%$ solution stored at room temperature showed no significant loss of potency after 3 days, while a brownish colour and an activity decrease of about $5 \%$ was observed after 10 days (Western Chemical, 2008). In addition, the fate of the substance in solution is poorly understood. Instructions to discard stock solutions after several days are too vague to interpret (Western Chemical, 2008; Argent, 2011). Further studies are required, especially regarding the effectiveness of solutions in relation to temperature, salinity and light. Thus, we recommend that solutions should be freshly prepared and kept in dark glass bottles.

\section{Anaesthetic efficacy and dosage}

The efficacy of MS-222 depends on environmental factors, i.e. temperature, oxygen content, $\mathrm{pH}$, hardness and salinity of water, and biological factors such as age, sex, size, weight, lipid content, fish species and density of biomass. Variations among species, size, maturity, and between individual fish should be considered when determining the dosage of the anaesthetic. Although increased temperature has been reported to shorten induction and recovery times in several teleost species (Houston and Woods, 1976; Sylvester and Holland, 1982; Hikasa et al., 1986; Bowser, 2001; Zahl et al., 2009), the importance of fish body size for the response to anaesthesia is less clear. Some studies demonstrate no relationship between body size and 
induction and recovery time, whereas others suggest that such a relationship does exist. Atlantic cod is an example of increasing induction and recovery time with increasing weight (Houston et al., 1976; Zahl et al., 2009). This suggests that the rate of absorption of the anaesthetic in relation to weight is slower in larger fish and may be a reflection of the smaller gill surface area in relation to body mass as a smaller area is available for drug diffusion relative to size. Regarding a diversity of factors influencing MS-222 efficacy with regard to fish size, Son et al. (2001) showed that smaller black rockfish (Sebastes schlegeli) were less resistant to the chemical than larger fish, although MS-222 effects differed with fish growth history, as fish cultured in embanked populations showed stronger resistance to anaesthetic stress, expressed in their earlier recovery and lower mortality compared to those cultured in land-based tanks or collected from wild stocks. Further studies should be conducted in challenge experiments in order to assess the size-related variations within fish species. An additional aspect to consider in MS-222 efficacy and dosage determination is a potentially reduced time to anaesthesia following repeated exposure. Unfortunately, investigation of this effect is rare. During weekly exposures in a study by Smith et al. (1999), hybrid tilapias previously exposed to MS-222 did not display a significantly reduced time to anaesthesia upon the second exposure, but did display significant reductions upon the third exposure and thereafter, suggesting that they did not respond to MS-222 with the typical enzyme induction-mediated tolerance reaction commonly observed with anaesthetics in mammals (Benson, 2002). Another important factor affecting xenobiotic flux across the dermal surface is the difference in skin anatomy in scaled and scaleless fish. Trout skin, for example, is covered with scales and has no taste buds. Catfish skin, on the other hand, has no scales and therefore these taste buds may offer channels via which chemicals can diffuse across the epidermis to the more vascularised dermis (McKim et al., 1996). MS-222 is fatsoluble, thus anaesthesia may last longer in larger or gravid fish and recovery may be slower as the drug is removed from the lipid reserves. Also, diseased or weakened animals are much more susceptible to anaesthetic treatment (Coyle et al., 2004). It is advisable to have fish fast for $12-24 \mathrm{~h}$ prior to anaesthesia or sedation. An additional aspect to consider while anaesthetising fish is their stocking density. Small variations in stocking density impacted the effectiveness of MS-222. Resistance to the drug increased when the density of test fish was increased from 0.3 to $0.9 \mathrm{~g} \mathrm{l}^{-1}$ in rainbow trout (Oncorhynchus mykiss), $\quad 0.4-1.2 \mathrm{~g} \mathrm{l}^{-1}$ in carp (Cyprinus carpio), and $0.3-0.8 \mathrm{~g}^{-1}$ in fathead minnows (Pimephales promelas) (Sylvester and Holland, 1982). Pharmaq (2010) recommends that during treatment, fish should be stocked at a density not exceeding $80 \mathrm{~g} \mathrm{l}^{-1}$, although studies are warranted to assess species-specific requirements. Due to the wide range of possible factors affecting its efficacy, and the complicated synergistic relationships among such factors, the specific applicative efficacy of MS-222 in a given host is often difficult to predict. Extensive literature data can be found on MS-222 usage on foodfish species, although little is available on its dosage for ornamental fish (Ross and Ross, 2008; Weber et al., 2009; Zahl et al., 2009)

Anaesthesia in fish can be divided into four stages (I-IV) and eight categories: (i) normal behaviour with active swimming; (ii) light sedation with slight loss of reactivity to visual and tactile stimuli and normal respiratory rate; (iii) deep sedation with cessation of voluntary swimming, and slight decrease of respiratory rate (comprising stage I anaesthesia); (iv) light narcosis where excitement phase may precede an increase in respiratory rate; (v) deep narcosis with total loss of equilibrium and slight reactivity to strong tactile and vibrational stimuli; (vi) light anaesthesia (comprising stage II anaesthesia) with further decrease in respiratory rate; (vii) surgical anaesthesia (or stage III anaesthesia) with total loss of reactivity; and (viii) medullary collapse with total loss of gill movement followed by cardiac arrest (stage IV) (Brown, 1993; Coyle et al., 2004). Although an aqueous solution of the substance prepared from the powder form is most often used as an immersion bath for temporary immobilisation, anaesthesia or sedation, large fish such as sharks and rays have been anaesthetized by spraying the gills with the MS-222 solution by means of a water pistol, bulb syringe, hand-pump or similar (Western Chemical, 2008). Before anaesthetising fish, it is recommended that the selected drug concentration and exposure time be tested on a small group of representative fish before medicating large numbers.

Doses for fish immersion are variable. A summary of studies assessing dose ranges, induction and recovery times is displayed in Table 1. The employed concentrations of MS222 depend on size and species of the fish and the reason for sedation or anaesthesia, with exposure times ranging from a few minutes for high concentrations and up to $48 \mathrm{~h}$ for low concentrations. Recovery takes place after 1 to $60+\mathrm{min}$, and during this period fish should be closely observed. Understanding the relationship between dose, exposure time and achieved anaesthetic stage ensures control of the procedure. The degree and nature of analgesia achieved and the ease of recovery are also important. Unfortunately, descriptions of these features are rarely available.

\section{Fish stress responses}

Fish show external and internal signs of stress, which are comparable to those described for higher vertebrates. Fish experiencing severe acute stress develop a stress response in which hormonal, biochemical, osmoregulatory, immune and energetic alterations take place (Ribas et al., 2007). Severe or chronic stress is often associated with poor performance and has been associated with immunosuppression in cultured fish (Iwama et al., 1989; Thomas and Robertson, 1991; Small, 2003; Palic et al., 2006).

The initial reaction to a stressful situation is associated with an activation of the neuroendocrine systems, leading to the release of hormones, i.e. catecholamines and corticosteroids. Catecholamines are released into the circulation within seconds following acute stress, though their concentration drops rapidly. Corticosteroids are released more slowly than the catecholamines, and elevated plasma levels return more slowly to basal values. Measurements of cortisol are therefore common in the assessments of the stress response in fish. An elevated level of stress hormones leads to a faster ventilation rate, increased branchial blood flow and increased cardiac output (Zahl et al., 2009). Along with cortisol, plasma glucose and chloride are physiological variables that respond to stressors, serving as indicators of the level of the stress response (Wagner et al., 2002). A fish in a state of acute stress anaesthetised through bath immersion will absorb the anaesthetic more rapidly and may also absorb a larger amount, thereby obtaining faster induction, deeper anaesthesia and delayed recovery (Zahl et al., 2009). Showing that the anaesthetics themselves may be stressors, Barton and Peter (1982) established that a 15-min exposure to $50 \mathrm{mg} \mathrm{l}^{-1} \mathrm{MS}-222$ 


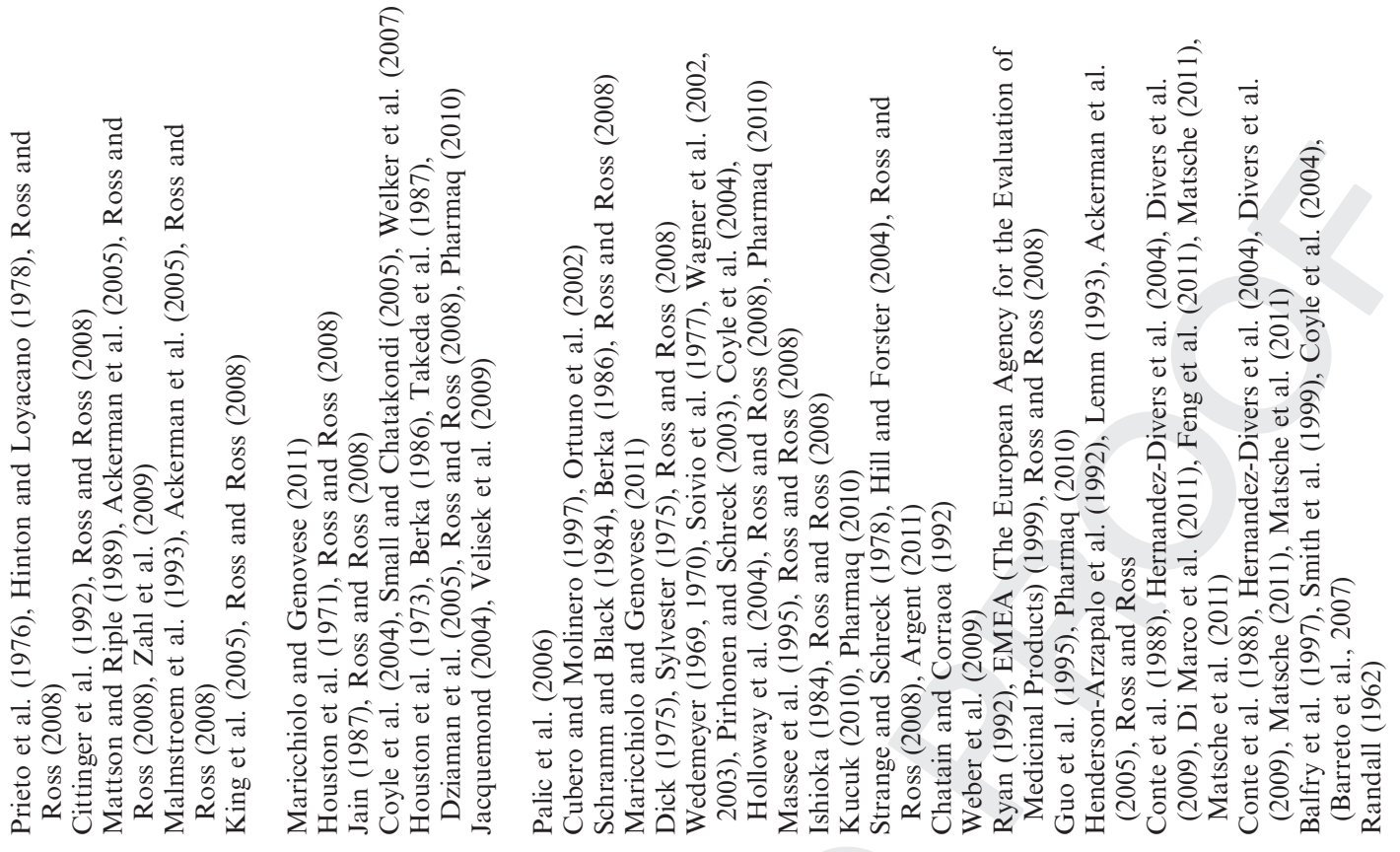

自

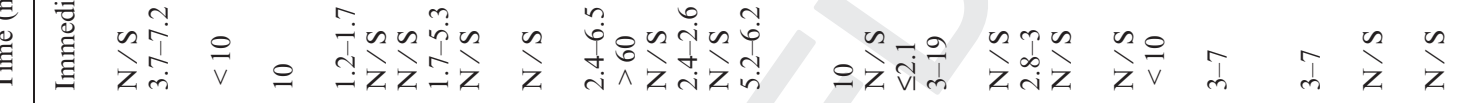

罗

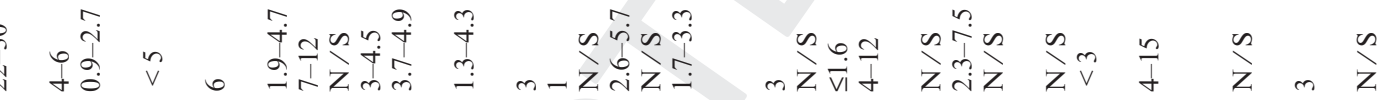

iิ

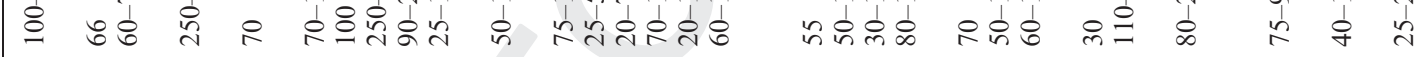

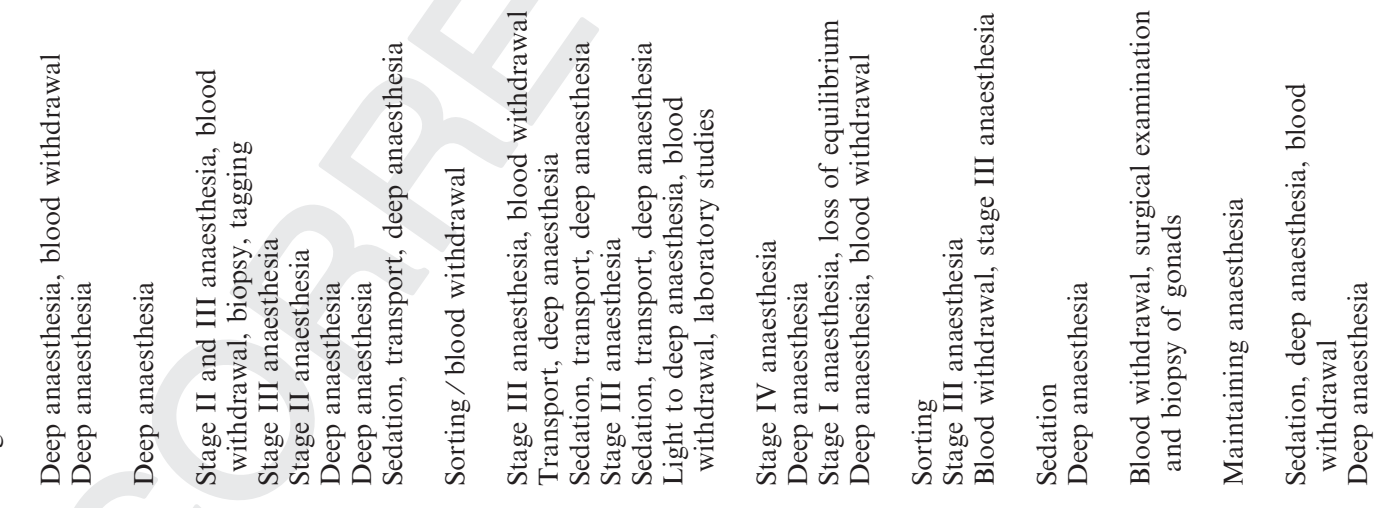
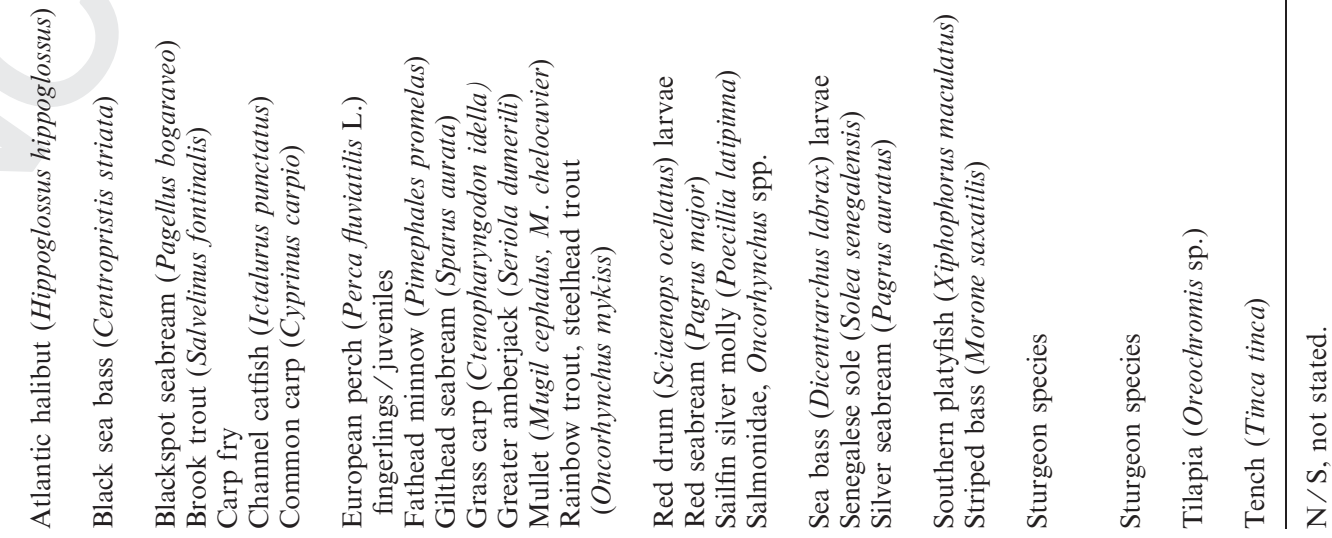
induced a stress response in juvenile rainbow trout. Therefore, MS-222 itself may act to increase cortisol levels, even when the fish are not subjected to physical stressors (Strange and Schreck, 1978; Davis et al., 1982; Small, 2003; Wagner et al., 2003). MS-222 yielded a similar increase in the cortisol concentration, as observed in fish exposed to handling and crowding stress without an anaesthetic (Small, 2003; Palic et al., 2006).

The slow induction of stage I anaesthesia during exposure to MS-222 may provide time for the fish to detect the anaesthetic agent due to its very distinctive chemical properties. It may be sensed through taste and smell and may also act as a skin irritant. Furthermore, as the anaesthetic starts to take effect, loss of balance may also elicit a stress response. Therefore, the length of time needed to induce anaesthesia is of importance. In both human and veterinary medicine, anaesthesia is often preceded by administration of a sedative to calm the patient and reduce any stress that might be caused by the anaesthetic or the anaesthetic procedure. Such pre-anaesthesia sedation has been tested with good results in several fish species, including salmon, in an attempt to reduce the stress response (EFSA, 2009a; Zahl et al., 2009, 2010).

The challenge is to establish a dosage of MS-222 that will not act as a stressor, especially since it is often difficult to disassociate the handling response from the experimental response. There is a also paucity of information regarding cortisol response to MS-222 for aquarium fish. An influential study (Crosby et al., 2006) on three-spot gourami (Trichogaster trichopterus), a commonly cultured tropical ornamental fish, evaluated plasma cortisol levels after handling stress and treatment with MS-222 $\left(60 \mathrm{mg} \mathrm{l}^{-1}\right)$ where treated fish had significantly lower cortisol levels than untreated controls. MS-222 was thus found to be beneficial in reducing handling stress of these obligate air breathers, which are difficult to sedate due to the labyrinth organ used for breathing air at the water's surface that allows maintaining a high level of activity in habitats with periodically low oxygen levels.

\section{Effects on fish physiology and blood properties}

The physiological consequences of MS-222 use have been well documented. Several authors illustrated that MS-222 could significantly alter fish blood plasma chemistry (Gingerich and Drottar, 1989; Harrington et al., 1991; Holloway et al., 2004). It impacts circulatory changes in the secondary lamellae in the form of vasodilatation and haemoconcentration (Soivio and Hughes, 1978). Anaesthesia induced with MS-222 contributed to hypoxemia, hypercapnia, respiratory acidosis and hyperglycemia in red pacu (Piaractus brachypomus) (Sladky et al., 2001). Due to hypoxia during MS-222 anaesthesia, blood glucose, lactate, potassium, sodium, magnesium, haemoglobin, haematocrit and lysozyme activity, and erythrocyte swelling have been reported to increase (Hattingh, 1977; Soivio et al., 1977; Brown, 1993; Cho and Heath, 2000; Sladky et al., 2001; Velisek et al., 2009). Urinary output and electrolyte loss also increased (Brown, 1993), although this did not affect postrecovery plasma chloride concentrations (Small and Chatakondi, 2005). Elevated plasma protein has also been associated with MS-222 anaesthesia of rainbow trout (Laidley and Leatherland, 1988). In gilthead seabream (Sparus aurata) blood glucose levels of anaesthetised fish were significantly higher than those of control fish (Ortuno et al., 2002). However, MS-222 had an inhibitory effect on glucose release in isolated hepatocytes from rainbow trout, likely due to stress-induced inhibition of glycogenolysis (Puceat et al., 1989).

Variability in blood chemistry highlights the importance of knowing the effect of the anaesthetic so as to not compromise blood plasma measurements that are integral to the experimental design. Suitable controls should thus be incorporated into the research design involving MS-222, particularly when variations in blood plasma chemistry parameters are being used as dependent variables. Also, the degree of central nervous system depression resulting from MS-222 use does not necessarily mitigate certain physiological responses, and findings of various experiments should also be viewed in respect of the dosage, exposure time, and phase of anaesthesia (induction/recovery). For example, Macavoy and Zaepfel (1997) reported increased haematocrit during acid stress and that the use of MS-222 to ease haematocrit sampling should not elevate measurements. They showed that exposure of blacknose dace (Rhinichtys atratulus) to 300 and $500 \mathrm{mg}^{-1}$ MS-222 did not raise haematocrit levels above those of controls. However, they collected blood samples only when fish attained the deepest inductive state with relatively high doses of MS-222. Although buffering of the anaesthetic solution is crucial regarding the acidity of the water, it also influences the physiological reaction to the anaesthetic. Administration of buffered MS-222 reduced the blood $\mathrm{pH}$ of freshwater fish (Soivio et al., 1977). When fish were anaesthetized with unbuffered solutions, blood urea nitrogen concentrations, hypercholinesteremia and ACTH production increased (Wedemeyer, 1970) whereas glucose levels decreased (Soivio et al., 1977).

MS-222 reduced feed intake after anaesthesia in rainbow trout. Non-anaesthetised fish ingested $15-20 \%$ more food than MS-222 anaesthetised fish, for up to $48 \mathrm{~h}$ (Pirhonen and Schreck, 2003). Application of MS-222 slightly altered internal organs and tissues (brain, muscle, liver, intestine sections) of rainbow trout, resulting in increased reactive oxygen species formation and leading to oxidative damage to lipids and proteins and the inhibition of antioxidant capacities (Velisek et al., 2011).

This anaesthetic reduced the contractile force of paced strips of the ventricular myocardium by almost $75 \%$ (Hill et al., 2002). During myography, it blocked vagal nerve transmission to the heart for Chinook salmon (Oncorchynchus tshawytcha) (at $100 \mathrm{mg}^{-1}$ ) and caused a $30-40 \%$ dilation of efferent and afferent branchial arteries (Hill et al., 2002). Heartbeat and respiratory frequency measurements of common carp exposed to concentrations of $75,100,125,150 \mathrm{mg} \mathrm{l}^{-1}$ revealed a concentration effect, with a similar recovery time in all treatments (Dziaman et al., 2005). Compared to unanaesthetized rainbow trout of variable size and similar water temperature, the heart rate was higher for trout exposed to $\mathbf{S}_{\mathbf{L}} 222$, which is consistent with parasympathetic inhibition in teleosts (Cotter and Rodnick, 2006). MS-222 anaesthesia in rainbow trout produced cardioacceleration followed by prolonged bradycardia. Cardioacceleration was found to be due to catecholamine release caused by the stress of exposure, and bradycardia was found to be produced by an increase in vagal tone caused by anoxia. All cardiac rates returned to normal within $8 \mathrm{~h}$ after removal from the anaesthetic solution (Lochowitz et al., 1974). Fredericks et al. (1993) reported that exposure of rainbow trout to MS-222 produced only minimal cardiovascular alterations, and that the mean dorsal aortic pressure decreased during exposure, whereas the heart rate and EKG patterns rapidly returned to normal. Depressed respiration, in combination with changes in blood oxygen and carbon 
dioxide levels, can cause changes to the heart rate and cardiac output, therefore it is important to aerate both induction and recovery baths (Carter et al., 2011).

\section{Pharmacokinetics following bath administration}

In order to establish correct dosage regimes and thereby promote optimal use, data derived from pharmacokinetic investigations are vital. Studies of elimination kinetics are also necessary in order to determine withdrawal times for drugs used in the production of food for human consumption (Kiessling et al., 2009). Absorption and elimination of MS-222 occurs by diffusion across the gill membranes (Wayson et al., 1976). Although eliminated primarily as the unmetabolized parent chemical, biotransformation to hydrolysis and acetylated products was noted (Kolanczyk et al., 2003). In adult spiny dogfish (Squalus acanthias) two major biotransformation pathways have been identified for MS-222. One pathway involved the hydrolysis of the ethyl group of MS-222 (the methane sulphonic acid salt of ethyl- $m$-aminobenzoate) to yield $m$-aminobenzoic acid followed by acetylation of the amine group to produce $m$-acetylaminobenzoic acid (Stenger and Maren, 1974). The second pathway involved the acetylation of the amine group to yield ethyl- $m$-aminobenzoate followed by hydrolysis of the original acetyl group to generate $m$-acetylaminobenzoic acid as the end product. These biotransformations occurred in liver and gills. In adult rainbow trout, MS-222 and ethyl- $m$-acetylaminobenzoate are excreted mainly via the kidney, while potencies of the metabolites of MS-222 have not been determined (Hunn et al., 1968). More recent findings speculate that none of the identified metabolites of the compound was pharmacologically active (EMEA, 1999). Based on literature data, if MS-222 is less toxic/effective than its metabolites, increased sensitivity with age could be explained by an increase in the activity of biotransformation pathways. Alternatively, if MS-222 were more toxic, one would need to evoke a decrease in the activity of biotransformation pathways to explain increased sensitivity with age (Rombough, 2007).

MS-222 was rapidly eliminated from Atlantic salmon (Salmo salar) plasma, while artificial ventilation during recovery increased the rate of elimination during the first 5-8 min before regaining respiration. Elimination of MS-222 was directly related to its water-soluble properties, indicating that this is an important factor to consider when setting withdrawal times (Kiessling et al., 2009). Also, MS-222 decreased the uptake of lipophilic compounds administered to fish (Sijm et al., 1993). Thus, its use has to be considered in certain trials since experimental methods significantly affected the pharmacokinetic variables that are used to model the bioconcentration of hydrophobic chemicals in the environment.

\section{Potential interference of MS-222 upon hepatic cytochrome P-450 spectra}

Metabolism, or the biotransformation of certain foreign hydrophobic compounds, including many therapeutic agents and environmental pollutants, is generally an enzymatic process. P-450 enzymes (P450) play important roles in the oxidation of structurally diverse chemicals. Multiple forms of $\mathrm{P} 450$ s existing in fish hepatic microsomes exhibit typical reduced $\mathrm{CO}$ absorption spectra, with a peak near $450 \mathrm{~nm}$. Reports on the effects of MS-222 on spectral measurements of hepatic microsomal cytochrome P450 are conflicting (Chevion et al., 1977; Fabacher, 1982; Kleinow et al., 1986). The MS-222 immersion overdose, although resulting in unambiguous immunoblots and catalytic activity, revealed atypical P450 spectra in the hepatic microsomes of summer flounder (Paralichtys dentatus) and hybrid striped bass (Morone saxatilis $\times M$. chryops). The vast majority of microsomes exhibited average maxima of $422 \mathrm{~nm}$ (personal data). According to Arinc and Sen (1994), a possible cause for the significant decrease of the $\mathrm{cP} 450$ content and activities may be anaesthesia of fish prior to removing livers for analysis, as in vivo benzocaine treatment decreased liver microsomal aniline 4-hydroxylase activity of gilthead seabream by $57 \%$. When brook trout were exposed to a water solution of MS-222 for 5 min, BP hydroxylase activity and cytochrome level were inhibited by 78 and $28 \%$, respectively. Kolanczyk et al. (2003) noted slight decreases in P450 levels following $2 \mathrm{~h}$ exposure of trout to $100 \mathrm{mg} \mathrm{l}^{-1} \mathrm{MS}-222$. Although not significant, they attributed this difference to P450 chemical interaction with MS-222, resulting in type II binding spectra, where the chemical bonds with the heme iron of cytochrome P450, and the spectrum shows a trough at $408 \mathrm{~nm}$ and peak at $428 \mathrm{~nm}$. Thus, MS-222 may influence the production of atypical P450 spectral measurements, which may have implications on P450 activity.

\section{Effects on nerve sensitivity}

Initially, absorption of MS-222 is rapid across the gills and quickly penetrates into the central nervous system (CNS), where it has an immediate effect on the autonomic nervous system to produce a form of 'vagus escape' (Treves-Brown, 2000). In fish, it produces general anaesthesia and inhibits neural signal transmission ranging from the periphery to higher parts of the nervous system. Although it has been suggested (Frazier and Narahashi, 1975; Neumcke et al., 1981; Arnolds et al., 2002) that the physiological effects of MS-222 on individual supramedullary/dorsal neurons are based on blocking sodium channels, its mechanism at the CNS level is not fully understood (Hara and Sata, 2007; Ueta et al., 2007). Critical drug concentrations are reached more rapidly with higher anaesthetic exposure levels, thus supporting the hypothesis that simple diffusion and osmotic pressure are principally responsible for the rapid uptake of MS-222 in snapper (Pagrus auratus). Loss of voluntary movement in snapper was dependent on the levels of anaesthetics in the blood and brain, implying that the effects of MS-222 were not only peripheral in the sodium channel (Ryan, 1992).

MS-222 had suppressive effects on peripheral and central neurons in acute preparations of numerous sensory systems, including electroreceptors, supramedullary/dorsal neurons and the lateral line (Palmer and Mensinger, 2004). The lateral line system provides a good model to determine the effects of anaesthesia on nerve excitability, since lateral line hair cells can be physiologically characterized and easily excited by external stimuli. Palmer and Mensinger (2004) showed that the dampening effect of MS-222 on the firing activity of the lateral line nerve is demonstrated by an increase in the interspike interval in response to increasing anaesthesia. Based on a study on the use of MS-222 during evoked potential audiometry in goldfish (Carassius auratus) (Cordova and Braun, 2007), it appeared that brief sedation $(<10 \mathrm{~min})$ did not alter auditory sensitivity. Also, since lower concentrations of MS-222 did not suppress firing in lateral line nerve fibres (Palmer and Mensinger, 2004), it may not be necessary to wait long periods 
of time following brief MS-222 anaesthesia before initiating an auditory-evoked potential. MS-222 significantly altered afferent input, spike height and the current needed to elicit an action potential of supramedullary/dorsal cells. Therefore, neurophysiological measurements must be interpreted with caution if MS-222 is used as a general anaesthetic. Zottoli et al. (2003) tested whether MS-222 affected physiological parameters of neurons having somata within the CNS. The transient use of MS-222 and the removal of the telencephalic hemispheres in that study had no residual effect on spike height, the current needed to elicit an action potential, or the ability to elicit post-synaptic potentials from the supramedullary/dorsal cells. Thus, the authors concluded that the transient use of MS-222 followed by removal of the telencephalon served as a reasonable precaution against the possibility that fish experience pain. There are opposing opinions as to whether fish experience pain, suggesting that there is an important difference between knowledge about sensation and sentience (EFSA, 2009b). Although the concept of pain in fish is still a matter of controversy, it is widely accepted that that they have the capacity for fear and suffering, possessing the same types of specialized receptors as birds and mammals that allow the detection of noxious stimuli (nociceptors). The area of pain perception and the effect of MS-222 would greatly benefit with novel data to bolster scientific understanding on the subject (Braithwaite and Boulcott, 2007; Rose, 2008; Ross and Ross, 2008). Research and developments in the area of cognition and brain imaging techniques in fish should be carried out to further the knowledge and understanding of pain perception, and the potential of anaesthesia to modulate nociception.

\section{Immune response and genotoxicity}

Anaesthesia may have immunodepressive effects in mammals; however, few authors have attempted to detect anaesthesiainduced immunodepression in fish (Ortuno et al., 2002). Circulating leucocyte counts are often used to assess the immunological health of fish. Specific changes were found in gilthead seabream anaesthetized with MS-222 in transport simulation (Cubero and Molinero, 1997), i.e. in the basophilic percentage drop, delay in acidophilic and basophilic response, and lymphoctopenia in thymus and pronephros. In a separate study on the same species, neither humoral nor cellular immune responses were depressed by MS-222 (Ortuno et al., 2002). The authors speculated that the reason that MS-222 did not depress haemolytic complement activity and phagocytic activity or influence respiratory burst activity of head-kidney leucocytes could be related to the dosage of the anaesthetic and / or its mode of action. Although the reason for the lack of immunodepression (which was demonstrated with three other investigated anaesthetics) was not elucidated, the authors suggested that it might be related to the direct interaction between the anaesthetic and immune components independent of stress signals. Further study is required to understand these observations and assess the possibilities of MS-222 induced immunodepression.

Erythrocytes are used as standard sentinel markers of genotoxic exposure in fish. The single cell gel comet assay was employed to assay MS-222 genotoxic effects on Nile tilapia (Oreochromis niloticus L.) erythrocytes (Barreto et al., 2007). No direct genotoxic activity was induced by MS-222 under either in vivo or in vitro conditions. Erythrocytes did not have DNA damage following in vivo bath exposure of fish to
MS-222. Similarly, in vitro treatments of erythrocytes with increasing doses of MS-222 did not induce a significant increase of DNA damage. No cytotoxicity was found following in vivo or in vitro MS-222 exposure. Other procaine analogues, typically used as local anaesthetics in humans, have tested negative for genotoxicity in different organisms, and therefore the authors suggested MS-222 to be a safe anaesthetic for use on fish (Barreto et al., 2007). However, further tests will be needed to explore the possible co-genotoxic effects of MS-222 in association with other genotoxins.

MS-222 could be used on fish prior to gamete harvesting without significant adverse impacts on gametes. Exposure of steelhead trout (Oncorhynchus mykiss) unfertilized eggs for 6 or $24 \mathrm{~h}$ to $225 \mathrm{mg} \mathrm{l}^{-1} \mathrm{MS}-222$ resulted in no reduction in egg fertility or embryo survival to hatch. However, higher doses reduced egg quality. Similarly, $3 \mathrm{~h}$ exposure to MS-222 $\left(225 \mathrm{mg}^{-1}\right)$ produced no significant effect on sperm motility in steelhead trout (Holcomb et al., 2004; Zydlewski et al., 2008). While anaesthesia had no impact on egg survival, in anaesthetised males direct contact between MS-222 and sperm affected the duration of sperm motility (Wagner et al., 2002). In a hatchery where MS-222 is to be used on broodstock, the general practice should be to dip the anaesthetized fish into a container of clean water prior to spawning to wash off residual anaesthetic that might interfere with fertilization.

\section{Fish euthanasia}

Euthanasia of both wild and captive fish is a common requirement in aquaculture and fisheries research for the lethal collection of tissues and blood. If a fish has to be killed, then death must occur with the least possible anxiety, pain and distress. MS-222 offers an alternative to other means of chemical or physical fish euthanasia, but is not permitted for use prior to slaughter for any purpose on any fish that might enter the food chain (EFSA, 2004). A concentration of $250 \mathrm{mg} \mathrm{l}^{-1}$ is the minimal concentration suggested by the AVMA for euthanasia of amphibians and fish (AVMA, 2007). A lethal dose of $400-500 \mathrm{mg}^{-1}$ is generally used for euthanasia of salmonids (Ackerman et al., 2005). For euthanasia, MS-222 is commonly used unbuffered (Callahan and Noga, 2002). In order to establish the most appropriate method for zebrafish (Danio rerio) euthanasia, both buffered and unbuffered solutions were used (Wilson et al., 2009). When unbuffered MS-222 was used to euthanize zebrafish, signs of distress occurred in $100 \%$ of fish with rapid opercular movements, with 39\% exhibited piping behaviour (gulping of air at the water surface). None of the animals exposed to the buffered MS-222 displayed rapid opercular movements. Interestingly, for 2 min past the last observable opercular movement, a significant number (17.4\%) of zebrafish exposed to unbuffered solution regained consciousness in the recovery tank. This finding suggests a need for closer monitoring when euthanizing animals. Indeed, few studies describe dose-response testing and reliability of euthanasia in different species.

In order for an overdose of anaesthetic to be a reliable and humane killing method for fish, more knowledge is needed before recommending the minimum dosage and exposure times for specific life stages, body sizes and water temperatures. Such information would help to ensure a minimum time to loss of consciousness and minimum induction of stress (EFSA, 2009a). Since stage III anaesthesia generally involves a cessation of breathing, which reduces gas transfer leading to hypoxia, respiratory acidosis and stress responses, prolonged 
maintenance of stage III anaesthesia without gill irrigation will result in death. Within that context, fish handlers should be concerned with the welfare of animals, as defined by the World Organisation for Animal Health (OIE). Good animal welfare requires, amongst other necessities, the humane handling and killing of fish (OIE Resolution, Article 7.1.1.). Fish welfare, however, has not been studied to the same extent as terrestrial farm mammals and birds, and neither welfare concepts nor welfare needs are clearly understood in the different fish species. For this reason, conscientious, good laboratory practice is always recommended when euthanizing fish with MS-222. For this method to be reliable, effective, and humane, the technical competence of the staff involved is paramount in all aspects of euthanasia.

\section{Concluding remarks}

Research to date has provided an abundance of data on MS222 usage in fish, although applications within these studies are often impractical at the farming level. Future efforts should be expanded to include studies on important farmed species (both marine and freshwater species, and ornamental fish), other than rainbow trout, as the present data are mainly the result of studying the effects of MS-222 on rainbow trout. Likewise, research is also needed on the use of MS-222 in juvenile fish, a critical period in the life cycle, as most MS-222 studies have been conducted on adult fish. In order to increase the efficiency and safety of this compound, several key issues should be highlighted and future perspectives recommended:

- MS-222 users, particularly in Europe, should follow updated regulations relating to the legal aspects of the methods and safety of its use in their countries, since this anaesthetic is not licensed in all countries. Also, there are differences regarding the permitted application purpose and withdrawal times. These legislative topics are a matter of high priority, and a common act should be suggested to decrease inconsistencies within the countries of a region.

- It is suggested that MS-222 solutions be buffered; although unbuffered solutions have higher safety margins in seawater, it was shown that this anaesthetic increased the acidity of the water. Buffering protocols need to be standardized, both for experimental and practical farm purposes. Further research is necessary on the possibilities of preparation and storage of solutions for easier administration, particularly for field studies.

- Safety margins, induction and recovery times for many fish species still need to be established and doses need to be recommended. Due to the wide range of possible factors affecting MS-222 efficacy, and their synergistic relationships, definition of its specific applicative efficiency for various species and various life stages is a challenging task.

- Although MS-222 anaesthesia benefits the fish by minimising the impact of a greater, more severe stressor, it is nonetheless stressful and the physiological effects on the stress response associated with MS-222 anaesthesia must be recognized.

- Substantial research has been conducted on the effects of this anaesthetic on fish physiology and blood properties, and an array of MS-222-induced changes has been documented. Caution should be exercised in research applications, since its effects on blood plasma hormones have not been adequately investigated in marine species. When comparing the results of variations in blood plasma chemistry between laboratories, care should be taken regarding the protocol of anaesthetisation so as not to compromise the physiological and blood plasma measurements integral to the experimental design.

- Pharmacokinetic investigations and elimination kinetic studies are needed to establish the correct dosage regimes and withdrawal times for different species. Also, the possible interference of MS-222 on the fish cytochrome P450 spectrum should be incorporated into trials due to its possible implications on P450 activity.

- Although the physiological effects of MS-222 on individual supramedullary/dorsal neurons are based on the blocking of sodium channels, its mechanism at the CNS level is not fully understood. Studies are required to assess the potential of MS-222 to induce immunodepression.

- Staff administering this anaesthetic should fully comply with the anaesthetization protocol, and preliminary tests should be performed with small numbers of fish in order to prevent accidental overdose. The desired level of anaesthesia should be controlled, all netting performed carefully, handling time reduced to a minimum, and fish behaviour and breathing rate monitored as they go through the various stages of anaesthesia. Technical competence of staff is vital.

Since anaesthetics administered to fish through bath immersions are equivalent to inhalation anaesthesia in human and veterinary medicine, when choosing the anaesthetic for a variety of potential uses on fish, one has to consider several of its properties such as effectiveness, safety for the fish, safety for the user and environment, effects on physiological and blood properties, stress induction, convenience of use, the nature of investigated experimental protocols and costs. Although MS-222 is relatively expensive, the beneficial characteristics will ensure its continuous application in aquaculture, whether for research, food production or ornamental fish rearing.

\section{References}

Ackerman, P. A.; Morgan, J. D.; Iwama, G. K., 2005: Anesthetics. In: CCAC (Canadian Council on Animal Care) Guidelines on the care and use of fish in research, teaching and testing, pp. 22 Available at: http://www.ccac.ca/Documents/Standards/Guidelines/Add_PDFs/Fish_Anesthetics.pdf (accessed on 17 June 2011).

AFS (American Fisheries Society), 2011: Guide to using drugs, biologics, and other chemicals in aquaculture, FCS Working Group On Aquaculture Drugs, Chemicals, and Biologics, pp. 65 February 2011. Available at: http://www.fws.gov/fisheries/aadap/ AFS-FCS\%20documents/GUIDE_FEB_2011.pdf (accessed on 8 June 2011).

Alpharma, 2001: Alpharma Animal Health Ltd. MS222 (Tricaine methane sulphonate) Technical Bulletin 5/2001, Revised 9/01, pp. 6 Available at: http://www.europharma.no/fiskehelse/datablad/bedovelse/MS222.pdf (accessed on 12 May 2011).

Argent, 2011: Argent Chemical Laboratories Inc. Finquel (ms-222) Brand of Tricaine Methanesulfonate. Fact Sheet, pp. 10 Available at: http://www.drugs.com/vet/finquel-ms-222-tricaine-methanesulfonate.html (accessed on 12 May 2011).

Arinc, E.; Sen, A., 1994: In vivo effects of the anaesthetic, benzocaine, on liver microsomal cytochrome P450 and mixed-function oxidase activities of gilthead seabream (Sparus aurata). Comp. Biochem. Physiol. C. 107, 399-404.

Arnolds, D. E. W.; Zottoli, S. J.; Adams, C. E.; Dineen, S. M.; Fevrier, S.; Guo, Y.; Pascal, A. J., 2002: Physiological effects of tricaine on the supramedullary / dorsal neurons of the cunner, Tautogolabrus adspersus. Biol. Bull. 203, 188-189.

AVMA (American Veterinary Medical Association), 2007: AVMA guidelines on euthanasia (Formerly: report of the AVMA Panel on Euthanasia) June 2007, pp. 39 Available at: http://www. 
avma.org/issues/animal_welfare/euthanasia.pdf (accessed on 28 April 2011)

Balfry, S. K.; Shariff, M.; Iwama, G. K., 1997: Strain differences in non-specific immunity of tilapia (Oreochromis niloticus) following challenge with Vibrio parahaemolyticus. Dis. Aquat. Org. 30, 7780 .

Barreto, R. E.; Gontijo, A. M. M. C.; Alves-de-Lima, R. O.; Raymundi, V. C.; Pinhal, D.; Reyes, V. A. V.; Volpato, G. L.; Salvadori, D. M. F., 2007: MS222 does not induce primary DNA damage in fish. Aquacult. Internat. 15, 163-168.

Barton, B. A.; Peter, R. E., 1982: Plasma cortisol stress response in fingerling rainbow trout, Salmo gairdneri Richardson, to various transport conditions, anaesthesia, and cold shock. J. Fish Biol. 20, 39-51.

Benson, G. J., 2002: Intravenous anesthetics. In: Veterinary anesthesia and pain management secrets, S. A. Greene (Ed.). Hanley \& Belfus Inc., Philadelphia, PA. pp. 91-96.

Berka, R., 1986: The transport of live fish. A review. EIFAC Technical Paper, 48. Food and Agriculture Organization of the United Nations. Rome, pp. 79.

Bernstein, P. S.; Digre, K. B.; Creel, D. J., 1997: Retinal toxicity associated with occupational exposure to the fish anesthetic MS222. Am. J. Ophthalmol. 12, 843-844.

Bowser, P. R., 2001: Anesthetic options for fish. In: Recent advances in veterinary anesthesia and analgesia: companion animals. R. D. Gleed, J. W. Ludders (Eds). International Veterinary Information Service, Ithaca, NY, USA. pp 1-3.

Braithwaite, V. A.; Boulcott, P., 2007: Pain perception, aversion and fear in fish. Dis. Aquat. Org. 75, 131-138.

Brown, L. A., 1993: Anaesthesia and restraint. In: Fish medicine, M. K. Stoskopf (Ed.). W. B. Saunders Co., Philadelphia, PA, USA. pp. 79-90.

Brown, R. S.; Eppard, M. B.; Murchie, K. J.; Nielsen, J. L.; Cooke, S. J., 2011: An introduction to the practical and ethical perspectives on the need to advance and standardize the intracoelomic surgical implantation of electronic tags in fish. Rev. Fish Biol. Fish. 21, $1-9$.

Burka, J. F.; Hammel, K. L.; Horsberg, T. E.; Johnson, G. R.; Rainnie, D. J.; Spears, D. J., 1997: Drugs in salmonid aquaculture - a review. J. Vet. Pharmacol. Ther. 20, 333-349.

Callahan, H. A.; Noga, E. J., 2002: Tricaine dramatically reduces the ability to diagnose protozoan ectoparasite (Ichthyobodo necator) infections. J. Fish Dis. 25, 433-437.

Carter, K. M.; Woodley, C. M.; Brown, R. S., 2011: A review of tricaine methanesulfonate for anesthesia of fish. Rev. Fish Biol. Fish. 21, 51-59.

CEC (Council of the European Communities), 1990: Council Regulation No. 2377/90/EEC laying down a community procedure for the establishment of maximum residue limits of veterinary medicinal products in foodstuffs of animal origin. Official $\mathrm{J}$. European Communities L224, 1-8.

Chatain, B.; Corraoa, D., 1992: A sorting method for eliminating larvae without functional swimbladders. Aquaculture, 107, 81-88.

Chevion, M.; Stegeman, J. J.; Peisach, J.; Blumberg, W. E., 1977: Electron paramagnetic resonance studies on hepatic microsomal cytochrome P-450 from a marine teleost fish. Life Sci. 20, 895900.

Cho, G. K.; Heath, D. D., 2000: Comparison of tricaine methanesulphonate (MS222) and clove oil anaesthesia effects on the physiology of juvenile Chinook salmon Oncorchynchus tshawytcha (Walbaum). Aquacult. Res. 31, 537-546.

Cittinger, C. A.; Holloway, H. L.; Derrig, T. M., 1992: Maintenance of juvenile paddlefish as experimental animals. Prog. Fish Cult. 54, 121-124.

Conte, F.; Doroshov, S.; Lutes, P., 1988: Hatchery manual for the white sturgeon. Publications Division of Agriculture and Natural Resources, Oakland, CA, USA.

Cordova, M. S.; Braun, C. B., 2007: The use of anesthesia during evoked potential audiometry in goldfish (Carassius auratus). Brain Res. 1153, 78-83.

Cotter, P. A.; Rodnick, K. J., 2006: Differential effects of anaesthetics on electrical properties of the rainbow trout (Oncorhynchus mykiss) heart. Comp. Biochem. Physiol. A. 145, 158-165.

Coyle, S. D.; Durborow, R. M.; Tidwell, J. H., 2004: Anesthetics in aquaculture. Southern Regional Aquaculture Center (SRAC) 3900, 1-6.

Crosby, T. C.; Hill, J. E.; Watson, C. A.; Yanong, R. P. E.; Strange, R., 2006: Effects of tricaine methanesulfonate, hypno, metomidate, quinaldine, and salt on plasma cortisol levels following acute stress in threespot gourami Trichogaster trichopterus. J. Aquat. Anim. Health. 18, 58-63.

Cubero, L.; Molinero, A., 1997: Confinement and anaesthetic exposure induces changes in the blood and tissue immune characteristics of gilthead sea bream. Dis. Aquat. Org. 31, 89-94.

Daniel, P., 2009: Available chemotherapy in Mediterranean fish farming: use and needs. In: Options Méditerranéennes A, The use of veterinary drugs and vaccines in Mediterranean aquaculture. C. Rogers and B. Basurco (Eds). Series A: Mediterranean Seminars, Zaragoza, CIHEAM / FAO, ISSN: 1016-121-X.

Davis, K. B.; Parker, N. C.; Suttle, M. A., 1982: Plasma corticosteroids and chlorides in striped bass exposed to tricaine methanesulfonate, quinaldine, etomidate, and salt. Prog. Fish Cult. 44, 205207.

Davis, M. W.; Stephenson, J.; Noga, E. J., 2008: The effect of tricaine on use of the fluorescein test for detecting skin and corneal ulcers in fish. J. Aquat. Anim. Health 20, 86-95.

Di Marco, P.; Petochi, T.; Longobardi, A.; Priori, A.; Finoia, M. G.; Donadelli, V.; Corsalini, I.; Marino, G., 2011: Efficacy of tricaine methanesulphonate, clove oil and medetomidine-ketamine and their side effects on the physiology of sturgeon hybrid Acipenser naccarii $\times$ Acipenser baerii. J. Appl. Ichthyol. 27, 611-617.

Dick, G. L., 1975: Some observations on the use of MS222 Sandoz with grey mullet (Mugil chelocuvier). J. Fish Biol. 7, 263-268.

Divers, S. J.; Boone, S. S.; Hoover, J. J.; Boysen, K. A.; Killgore, K. J.; Murphy, C. E.; George, S. G.; Camus, A. C., 2009: Field endoscopy for identifying gender, reproductive stage and gonadal anomalies in free-ranging sturgeon (Scaphirhynchus) from the lower Mississippi River. J. Appl. Ichthyol. 25, 68-74.

Dziaman, R.; Klyszejko, B.; Hajek, G., 2005: The effect of MS-222 on the cardiac and respiratory function and behaviour of common carp, Cyprinus carpio L. during general anaesthesia. Acta Ichthyol. Piscat. 35, 125-131.

EFSA (European Food Safety Authority), 2004: Welfare aspects of the main systems of stunning and killing the main commercial species of animals. Opinion of the Scientific Panel on Animal Health and Welfare on a request from the Commission. The EFSA J. 45, $1-29$.

EFSA (European Food Safety Authority), 2008: Scientific report of EFSA prepared by Working Group on seabass / seabream welfare on Animal Welfare Aspects of Husbandry Systems for Farmed European seabass and gilthead seabream. Annex I to. The EFSA J. 844, 1-89.

EFSA (European Food Safety Authority), 2009a: Welfare aspects of stunning and killing Atlantic salmon. Stunning and killing of farmed salmon. The EFSA J. 1012, 25-77.

EFSA (European Food Safety Authority), 2009b: General approach to fish welfare and to the concept of sentience in fish. Scientific Opinion of the Panel on Animal Health and Welfare. The EFSA J. 954, 1-27.

EMEA (The European Agency for the Evaluation of Medicinal Products), 1999: Committee for Veterinary Medicinal Products, Tricaine Mesilate, Summary Report. 1-4 April 1999, pp. 4 Available at: http://www.ema.europa.eu/docs/en_GB/document_library/ Maximum_Residue_Limits_-_Report/2009/11/WC500015660.pdf (accessed on 27 April 2011).

Fabacher, D. L., 1982: Hepatic microsomes from freshwater fish-II. Reduction of benzo(a)pyrene metabolism by the fish anesthtics quinaldine sulphate and tricaine. Comp. Biochem. Physiol. C. 73, 285-288.

FDA(U.S. Food and Drug Administration), 2006: Database of approved animal drug products. U.S. Department of Health and Human Services, Food and Drug Administration, Center for Veterinary Medicine. VMRCVM Drug Information Laboratory. Available at: http://www.accessdata.fda.gov/scripts/AnimalDrugsAtFDA/. (accessed on 15 April 2011).

Feng, G.; Zhuang, P.; Zhang, L.; Kynard, B.; Shi, X.; Duan, M.; Liu, J.; Huang, X., 2011: Effect of anaesthetics MS-222 and clove oil on blood biochemical parameters of juvenile Siberian sturgeon (Acipenser baerii). J. Appl. Ichthyol. 27, 595-599.

Frazier, D. T.; Narahashi, T., 1975: Tricaine (MS-222): effects on ionic conductances of squid axon membranes. Eur. J. Pharmacol. 33, 313-317.

Fredericks, K. T.; Gingerich, W. H.; Fater, D. C., 1993: Comparative cardiovascular effects of four fishery anesthetics in spinally transacted rainbow trout, Oncorhynchus mykiss. Comp. Biochem. Physiol. C Pharmacol. Toxicol. Endocrinol. 104, 477-483. 
Gingerich, W. H.; Drottar, K. R., 1989: Plasma catecholamine concentrations in rainbow trout (Salmo gairdneri) at rest and after aesthesia and surgery. Gen. Comp. Endocr. 73, 390-397.

Guo, F. C.; Teo, L. H.; Chen, T. W., 1995: Effects of anaesthetics on the water parameters in a simulated transport experiment of platyfish, Xiphophorus maculates (Guenther). Aquacult. Res. 26, $265-271$.

Hara, K.; Sata, T., 2007: The effects of the local anaesthetics lidocaine and procaine on glycine and gamma-aminobutyric acid receptor expressed in xenopus oocytes. Anaesth. Analg. 104, 1434-1439.

Harrington, A. J.; Russell, K. A.; Singer, T. D.; Ballantyne, J. S., 1991: The effects of tricaine methanesulphonate (MS-222) on plasma nonesterified fatty acids in rainbow trout, Oncorhynchus mykiss. Lipids 26, 774-775

Hattingh, J., 1977: The effect of tricaine methanesulphonate (MS-222) on the microhaematocrit of fish blood. J. Fish Biol. 10, 453-455.

Henderson-Arzapalo, A.; Lemm, C.; Hawkinson, J.; Keyes, P., 1992 Tricaine used to separate phase 1 striped bass with uninflated swimbladders from normal fish. Prog. Fish Cult. 54, 133-135.

Hernandez-Divers, S. J.; Bakal, R. S.; Hickson, B. H.; Rawlings, C. A.; Wilson, H. G.; Radlinsky, M.; Hernandez-Divers, S. M.; Dover, S. R., 2004: Endoscopic sex determination and gonadal manipulation in Gulf of Mexico sturgeon (Acipenser oxyrinchus desotoi) J. Zoo Wildl. Med. 35, 459-470.

Hikasa, Y.; Takase, K.; Ogasawara, T.; Ogasawara, S., 1986: Anesthesia and recovery with tricaine methanesulfonate, eugeno and thiopental sodium in the carp, Cyprinus carpio. Jpn. J. Vet. Sci. 48, 341-351.

Hill, J. V.; Forster, M. E., 2004: Cardiovascular responses of Chinook salmon (Oncorhynchus tshawytscha) during rapid anaesthetic induction and recovery. Comp. Biochem. Physiol. 137, 167-177.

Hill, J. V.; Davison, W.; Forster, M. E., 2002: The effects of fish anaesthetics (MS222, metomidate and AQUI-S) on heart ventricle, the cardiac vagus and branchial vessels from Chinook salmon (Oncorhynchus tshawytscha). Fish Physiol. Biochem. 27, $19-28$.

Hinton, M. J.; Loyacano, H. A., 1978: Efficacy of quinaldine and MS222 on American eel. J. World Aquacult. Soc. 9, 647-652.

Holcomb, M.; Woolsey, J.; Cloud, J. G.; Ingermann, R. L., 2004: Effects of clove oil, tricaine, and $\mathrm{CO}_{2}$ on gamete quality in steelhead and white sturgeon. N. Am. J. Aquacult. 66, 228-233.

Holloway, A. C.; Keene, J. L.; Noakes, D. G.; Moccia, R. D., 2004 Effects of clove oil and MS-222 on blood hormone profiles in rainbow trout Oncorhynchus mykiss, Walbaum. Aquacult. Res. 35, 1025-1030.

Houston, A. H.; Woods, R. J., 1976: Influence of temperature upon tricaine methane sulphonate uptake and induction of anesthesia in rainbow trout (Salmo gairdneri). Comp. Biochem. Physiol. 54C, $1-6$

Houston, A. H.; Madden, J. A.; Woods, R. J.; Miles, H. M., 1971: Some physiological effects of handling and tricaine methanesulphonate anaesthetization upon the Brook Trout, Salvelinus fontalis. J. Fish. Res. Board Can. 28, 625-633.

Houston, A. H.; Czerwinski, C. L.; Woods, R. J., 1973: Cardiovascular and respiratory activity during recovery from anaesthesia and surgery in brook trout (Salvelinus fontinalis) and carp (Cyprinu. carpio). J. Fish. Res. Board Can. 30, 1705-1712.

Houston, A. H.; Corlett, J. T.; Woods, R. J., 1976: Specimen weight and MS-222. J. Fish. Res. Board Can. 33, 1403-1407.

Hunn, J. B.; Schoettger, R. A.; Willford, W. A., 1968: Turnover and urinary excretion of free and acetylated M.S. 222 by rainbow trout, Salmo gairdneri. J. Fish. Res. Board Can. 25, 25-31.

Ishioka, H., 1984: Physiological and biochemical studies on the stress responses of the red sea bream, Pagrus major (Temminck et Schlegel). Bull. Nansei Reg. Res. Lab. 17, 1-133.

Iwama, G. K.; McGeer, J. C.; Pawluk, M. P., 1989: The effects of five fish anaesthetics on acid-base balance, hematocrit, blood gases, cortisol, and adrenaline in rainbow trout. Can. J. Zool. 67, 20652073

Jacquemond, F., 2004: Sorting Eurasian perch fingerlings (Perca fluviatilis L.) with and without functional swim bladder using tricaine methane sulfonate. Aquaculture 231, 249-262.

Jain, S. M., 1987: Use of MS-222 as an anaesthetic agent for young common carp Cyprinus carpio. J. Inland Fish. Soc. India. 19, 6770.

Jennings, C. A.; Looney, G. L., 1998: Evaluation of two types of anesthesia for performing surgery on striped bass. N. Am. J. Fish. Manage. 18, 187-190.
Kiessling, A.; Johansson, D.; Zahl, I. H.; Samuelsen, O. B., 2009: Pharmacokinetics, plasma cortisol and effectiveness of benzocaine, MS-222 and isoeugenol measured in individual dorsal aorta-cannulated Atlantic salmon (Salmo salar) following bath administration. Aquaculture 286, 301-308.

King, W.; Hooper, B.; Hillsgrove, S.; Benton, C.; Berlinsky, D. L., 2005: The use of clove oil, metomidate, tricainemethanesulphonate and 2-phenoxyethanol for inducing anaesthesia and their effect on the cortisol stress response in black sea bass (Centropristis striata L.). Aquac. Res. 36, 1442-1449.

Kleinow, K. M.; Haasch, M. L.; Lech, J. J., 1986: The effect of tricaine anesthesia upon induction of select P-450 dependent monooxygenase activities in rainbow trout (Salmo gairdneri). Aquat. Toxicol. 8, 231-241.

Kolanczyk, R. C.; Fitzsimmons, P. N.; McKim, J. M.; Erickson, R. J.; Schmieder, P. K., 2003: Effects of anaesthesia (tricaine methanesulfonate, MS222) on liver biotransformation in rainbow trout (Onorhynchus mykiss). Aquat. Toxicol. 64, 177-184.

Kucuk, S., 2010: Efficacy of tricaine on Poecilia latipinna at different temperatures and concentrations. Afr. J. Biotechnol. 9, 755-759.

Laidley, C. W : Leatherland, J. F., 1988: Cohort sampling, anaesthesia and stocking-density effects on plasma cortisol, thyroid hormone, metabolite and ion levels in rainbow trout, Salmo gairdneri Richardson. J. Fish Biol. 33, 73-88.

Lemm, C. A., 1993: Evaluation of five anesthetics on striped bass. National Fisheries Research Centre Technical Report 196, National Fisheries Research Center B Leetown, Kearneysville WV. pp. 17.

Lewbart, G. A.; Butkus, D. A.; Papich, M. G.; Coleman, A. K.; Krum, H. N.; Noga, E. J., 2005: Evaluation of a method of intracoelomic catheterization in koi. J. Am. Vet. Med. Assoc. 226, 784-788.

Lochowitz, R. T.; Miles, H. M.; Hafemann, D. R., 1974: Anestheticinduced variations in the cardiac rate of the teleost, Salmo gairdneri. Comp. Gen. Pharmacol. 5, 217-224.

Macavoy, S. E.; Zaepfel, R. C., 1997: Effects of tricaine methanesulfonate (MS-222) on hematocrit: first field measurements on blacknose dace. Trans. Am. Fish. Soc. 126, 500-503.

Malmstroem, T.; Salte, R.; Gjoeen, H. M.; Linseth, A., 1993: A practical evaluation of metomidate and MS-222 as anaesthetics for Atlantic halibut (Hippoglossus hippoglossus L.). Aquaculture $113,331-338$

Maricchiolo, G.; Genovese, L., 2011: Some contributions to knowledge of stress response in innovative species with particular focus on the use of the anaesthetics. Open Mar. Biol. J. 5, 24-33.

Massee, K. C.; Rust, M. B.; Hardy, R. W.; Stickney, R. R., 1995: The effectiveness of tricaine, quinadine sulphate and metomidate as anesthetics for larval fish. Aquaculture 134, 351-359.

Matsche, M. A., 2011: Evaluation of tricaine methanesulfonate (MS-222) as a surgical anesthetic for Atlantic sturgeon Acipenser oxyrinchus oxyrinchus. J. Appl. Ichthyol. 27, 600-610.

Matsche, M. A.; Bakal, R. S.; Rosemary, K. M., 2011: Use of laparoscopy to determine sex and reproductive status of shortnose sturgeon (Acipenser brevirostrum) and Atlantic sturgeon (Acipenser oxyrinchus oxyrinchus). J. Appl. Ichthyol. 27, 627-636.

Mattson, N. S.; Riple, T. H., 1989: Metomidate, a better anesthetic for cod (Gadus Morhua) in comparison with benzocaine, MS-222, chlorobutanol, and phenoxyethanol. Aquaculture 83, 89-94.

McKim, J. M.; Nichols, J. W.; Lien, G. J.; Hoffman, A. D.; Gallinat, C. A.; Stokes, G. N., 1996: Dermal absorption of three waterbone chloroethanes in rainbow trout (Oncorhynchus mykiss) and channel catfish (Ictalurus punctatus). Fund. Appl. Toxicol. 31, 218-228.

McKim, J. M.; Kolanczyk, R. C.; Lien, G. J.; Hoffman, A. D., 1999: Dynamics of renal excretion of phenol and major metabolites in the rainbow trout (Onorhynchus mykiss). Aquat. Toxicol. 45, 265277

Milligan, C. L.; Wood, C. M., 1982: Disturbances in haematology, fluid volume distribution and circulatory function associated with low environmental $\mathrm{pH}$ in the rainbow trout, Salmo gairdneri. J. Exp. Biol. 99, 397-415.

Neumcke, B.; Schwartz, W.; Stampfili, R., 1981: Block of Na channels in the membrane of myelinated nerve by benzocaine. Pflügers Arch. 390, 230-236.

Ohr, E. A., 1976: Tricaine methanesulfonate-I. pH and its effect on aesthetic potency. Comp. Biochem. Physiol. C. 54, 13-17.

Ortuno, J.; Esteban, M. A.; Meseguer, J., 2002: Effects of four anaesthetics on the innate immune response of gilthead seabream (Sparus aurata L.). Fish Shellfish Immunol. 12, 49-59. 
Packer, R. K., 1979: Acid-base balance and gas exchange in brook trout (Salvelinus fontainalis) exposed to acidic environments. J. Exp. Biol. 79, 127-134.

Palic, D.; Herolt, D. M.; Andreasen, C. B.; Menzel, B. W.; Roth, J. A., 2006: Anaesthetic efficacy of tricaine methanesulfonate, metomidate and eugenol: Effects on plasma cortisol concentration and neutrophil function in fathead minnows (Pimephales promelas Rafinesque, 1820). Aquaculture 254, 675-685.

Palmer, L. M.; Mensinger, A. F., 2004: Effect of the anesthetic tricaine (MS-222) on nerve activity in the anterior lateral line of the oyster toadfish, Opsanus tau. J. Neurophysiol. 92, 1034-1041.

Pelster, B.; Randall, D., 1998: The physiology of the root effect. In: Fish physiology, vol 17. S. F. Perry and B. Tufts (Eds). Academic Press, New York, pp. 113-139.

Pharmaq, 2010: Pharmaq Technical Bulletin, Pharmaq Ltd. United Kingdom, pp 6 Available at: http://www.vmd.defra.gov.uk/ProductInformationDatabase/SPC./SPC_88144.doc (accessed on April 10, 2011).

Piper, R. G.; McElwain, I. B.; Orme, L. E.; McCraren, J. P.; Fowler, L. G.; Leonard, J. R., 2001: Hatchery requirements. In: Fish hatchery management, G. A. Wedemeyer (Ed.). American Fisheries Society, Bethesda, MD. pp. 11-12.

Pirhonen, J.; Schreck, C. B., 2003: Effects of anaesthesia with MS222, clove oil and $\mathrm{CO}_{2}$ on feed intake and plasma cortisol in steelhead trout (Oncorchynchus mykiss). Aquaculture 220, 507514.

Pramod, P. K.; Sajeevan, T. P.; Ramachandran, A.; Sunesh Thampy, A.; Somnath Pai, S., 2010: Effects of two anesthetics on water quality during simulated transport of a tropical ornamental fish, the Indian tiger barb Puntius filamentosus. N. Am. J. Aquacult. 72, 290-297.

Prieto, A.; Fajer, E.; Barrera, M... 1976: Utilizacion del MS222 en la anguilla americana (Anguilla rostrata, Le Suer). Contribuciones del Direccion de Acuicultura, La Habana, Cuba. (in Spanish)

Puceat, M.; Garin, D.; Freminet, A., 1989: Inhibitory effect of anaesthesia with 2-phenoxyetanol as compared to MS222 on glucose release in isolated hepatocytes from rainbow trout (Salmo gairdneri). Comp. Biochem. Physiol. 94, 221-224.

Randall, D. J., 1962: Effect of anaesthetic on the heart and respiration of a teleost fish. Nature London, 195, 506.

Redman, S. D.; Meinertz, J. R.; Gaikowski, M. P., 1998: Effects of immobilization by electricity and MS-222 on brown trout broodstock and their progeny. Prog. Fish Cult. 60, $44-49$.

Ribas, L.; Flos, R.; Reig, L.; MacKenzie, S.; Barton, B. A.; Tort, L., 2007: Comparison of methods for anaesthetizing Senegal sole (Solea senegalensis) before slaughter: stress responses and final product quality. Aquaculture 269, 250-258

Rombough, P. J., 2007: Ontogenetic changes in the toxicity and efficacy of the anaesthetic MS222 (tricaine methanesulfonate) in zebrafish (Danio rerio) larvae. Comp. Biochem. Physiol. A, 148, 463-469.

Rose, J. D., 2008: The neurobehavioral nature of fishes and the question of awareness and pain. Rev. Fish. Sci. 10, 1-38.

Ross, L. G.; Ross, B., 2008: Anaesthetic and Sedative Techniques for Aquatic Animals. 3rd edn. Blackwell Publishing Ltd, ??????, pp. 240.

Ryan, S., 1992: The dynamics of MS-222 anaesthesia in a marine teleost (Pagrus auratus: Sparidae). Comp. Biochem. Physiol. C. 101, 593-600.

Schramm, H. L.; Black, D. J., 1984: Anaesthesia and surgical procedures for implanting radio transmitters into grass carp. Prog. Fish Cult. 46, 185-190.

Sigma, 2007: Material Safety Data Sheet, Sigma-Aldrich Corporation. Available at: http://www.sigmaaldrich.com/catalog/ProductDetail. do? $77=0 \& N 5=$ SEARCH CONCAT PNO BRAND KEY\& $\mathrm{N} 4=\mathrm{A} 5040 \mid \mathrm{FLUKA} \& \mathrm{~N} 25=0 \& \mathrm{QS}=\mathrm{ON} \& \mathrm{~F}=\mathrm{SPEC} . \quad$ (accessed on June 10, 2011).

Sijm, D. T. H. M.; Bol, J.; Sinen, W.; Opperhuizen, A., 1993: Ethyl $\mathrm{m}$-aminobenzoate methanesulfonate dependent and carrier dependent pharmacokinetics of extremely lipophilic compounds in rainbow trout. Arch. Environ. Contam. Toxicol. 25, 102-109.

Sinclair, L., 2004: Euthanasia in the animal shelter. In: Shelter medicine for veterinarians and staff. L. Miller and S. Zawistowski (Eds), Blackwell Publishing Ltd. Oxford, UK, pp. 389-410.

Sladky, K. K.; Swanson, C. R.; Stoskopf, M. K.; Loomis, M. R.; Lewbart, G. A., 2001: Comparative efficacy of tricaine methanesulfonate and clove oil for use as anesthetics in red pacu (Piaractus brachypomus). Am. J. Vet. Res. 62, 337-342.
Small, B. C., 2003: Anaesthetic efficacy of metomidate and comparison of plasma cortisol responses to tricaine methanesulfonate, quinaldine and clove oil anaesthetized channel catfish Ictalurus punctatus. Aquaculture 218, 177-185.

Small, B. C.; Chatakondi, N., 2005: Routine measures of stress are reduced in mature channel catfish during and after AQUI-S anesthesia and recovery. N. Am. J. Aquacult. 67, 72-78.

Smit, G. L.; Hattingh, J., 1979: Anaesthetic potency of MS 222 and neutralized MS 222 as studied in three freshwater species. Comp. Biochem. Physiol. 62C, 237-241.

Smit, G. L.; Schoonbee, H. J.; Barham, W. T., 1977: Some effects of the anaesthetic MS 222 on freshwater bream. S. Afr. J. Sci. 73, $351-352$

Smith, D. A.; Smith, S. A.; Holladay, S. D., 1999: Effect of previous exposure to tricaine methanesulfonate on time to anaesthesia in hybrid tilapias. J. Aquat. Anim. Health. 11, 183-186.

Soivio, A.; Hughes, G. M., 1978: Circulatory changes in secondary lamellae of Salmo gairdneri gills in hypoxia and anaesthesia. Ann. Zool. Fenn. 15, 221-225.

Soivio, A.; Nyholm, K.; Huhti, M., 1977: Effects of anaesthesia with MS222, neutralized MS222, and benzocaine on the blood constituents of rainbow trout, Salmo gairdneri. J. Fish Biol. 10, 91-101.

Son, M.-H.; Park, M.-W.; Myeong, J.-I.; Kim, D.-J.; Kim, B.-H.; Jo, Q.; Jeon, I.-G., 2001: Anaesthetic tolerance of juvenile black rockfish Sebastess schlegeli produced for wild stock enhancement. Ocean Polar Res. 23, 285-290.

Spaeth, M.; Schweickert, W., 1977: The effect of metacaine (MS-222) on the activity of the efferent and afferent nerves in the teleost lateral line system. Naunyn Schmiedebergs Arch. Pharmacol. 297, $9-16$

Stenger, V. G.; Maren, T. H., 1974: The pharmacology of MS-222 (ethyl-m-aminobenzoate) in Squalus acanthias. Comp. Gen. Pharmacol. 5, 23-35.

Strange, R. J.; Schreck, C. B., 1978: Anesthetic and handling stress on survival and cortisol concentration in yearling Chinook salmon (Oncorhynchus tshawytscha). Can. J. Fish. Aquat. Sci. 35, 349349.

Sylvester, J. R., 1975: Factors influencing the efficacy of MS222 to striped mullet (Mugil cephalus). Aquaculture 6, 163-169.

Sylvester, J. R.; Holland, L. E., 1982: Influence of temperature, water hardness, and stocking density on MS-222 response in three species of fish. Prog. Fish-Cult. 44, 138-141.

Takeda, T.; Yamasaki, K.; Itazawa, Y., 1987: Effect of MS222 on respiration and efficacy of forced branchial irrigation with the anesthetic solution in carp. Bull. Jpn. J. Sci. Fish. 53, 1701-1709.

Tapper, M. A.; Sheedy, B. R.; Hammermeister, D. E.; Schmieder, P. K., 2000: Depletion of cellular protein thiols as an indicator of arylation in isolated trout hepatocytes exposed to 1,4-benzoquinone. Toxicol. Sci. 55, 327-334.

Thomas, P.; Robertson, L., 1991: Plasma cortisol and glucose stress responses of red drum (Sciaenops ocellatus) to handling and shallow water stressors and anaesthesia with MS-222, quinaldine sulfate and metomidate. Aquaculture 96, 69-86.

Treves-Brown, K. M., 2000: Applied fish pharmacology. Kluwer Acad. Publishers, Dordrecht/London, pp. 309.

Ueta, K.; Suzuki, T.; Sugimoto, M.; Uchida, I.; Mashimoto, T., 2007: Local anaesthetics have different mechanisms and sites of action at recombinant 5- $\mathrm{HT}_{3}$ receptors. Reg. Anesth. Pain Med. 32, 462 470 .

Velisek, J.; Stejskal, V.; Kouril, J.; Svodobova, Z., 2009: Comparison of the effects of four anaesthetics on biochemical blood profiles of perch. Aquacult. Res. 40, 354-361.

Velisek, J.; Stara, A.; Li, Z.-H.; Silovska, S.; Turek, J., 2011: Comparison of the effects of four anaesthetics on blood biochemical profiles and oxidative stress biomarkers in rainbow trout. Aquaculture 310, 369-375.

Wagner, E.; Arndt, R.; Hilton, B., 2002: Physiological stress responses, egg survival and sperm motility for rainbow trout broodstock anesthetized with clove oil, tricaine methanesulfonate or carbon dioxide. Aquaculture 211, 353-366.

Wagner, G. N.; Singer, T. D.; McKinley, R. S., 2003: The ability of clove oil and MS-222 to minimize handling stress in rainbow trout (Oncorhynchus mykiss Walbaum). Aquacult. Res. 34, 1139-1146.

Wayson, K. A.; Downes, H.; Lynn, R. K.; Gerber, N., 1976: Studies on the comparative pharmacology and selective toxicity of tricaine methanesulfonate: metabolism as a basis of the selective toxicity in poikilotherms. J. Pharmacol. Exp. Ther. 198, 695-708. 
Weber, R. A.; Peleteiro, J. B.; Garcia Martin, L. O.; Aldegunde, M., 2009: The efficacy of 2-phenoxyethanol, metomidate, clove oil and MS-222 as anaesthetic agents in the Senegalese sole (Solea senegalensis Kaup 1858). Aquaculture 288, 147-150.

Wedemeyer, G., 1969: Stress-induced ascorbic acid depletion and cortisol production in two salmonid fishes. Comp. Biochem. Physiol. 29, 1247-1251.

Wedemeyer, G., 1970: Stress of anesthesia with MS222 and benzocaine in rainbow trout. Can. J. Fish. Aquat. Sci. 27, 909-914.

Welker, T. L.; Lim, C.; Yildirim-Aksoy, M.; Klesius, P. H., 2007: Effect of buffered and unbuffered tricaine methanesulfonate (MS222) at different concentrations on the stress responses of channel catfish, Ictalurus punctatus Rafinesque. J. Appl. Aquacult. $19,1-18$.

Western Chemical, 2008: Tricaine-S, fact sheet. Western Chemical, Inc. WA, USA, pp. 9 Available at: http://www.wchemical.com/ Assets/File/tricaineS_instructions.pdf (accessed on June 10, 2011).

Wilson, J. M. Bunte, R. M.; Carty, A. J., 2009: Evaluation of rapid cooling and tricaine methanesulfonate (MS222) as methods of euthanasia in zebrafish (Danio rerio). J. Am. Assoc. Lab. Anim. Sci. 48, 785-789.

Xu, D.-H.; Shoemaker, C. A.; Klesius, P. H., 2008: Effect of tricaine methanesulfonate on survival and reproduction of the fish ectoparasite Ichthyophthirius multifiliis. Parasitol. Res. 103, 979 982.
Yoshimura, H.; Nakamura, M.; Koeda, T., 1981: Mutagenicity screening of anesthetics for fishes. Mutat. Res. 90, 119-124.

Zahl, I. H.; Kiessling, A.; Samuelsen, O. B.; Hansen, M. K., 2009: Anaesthesia of Atlantic cod (Gadus morhua) - Effect of preanaesthetic sedation, and importance of body weight, temperature and stress. Aquaculture 295, 62-69.

Zahl, I. H.; Kiessling, A; Samuelsen, O. B; Olsen, R. E., 2010: Anesthesia induces stress in Atlantic salmon (Salmo salar), Atlantic cod (Gadus morhua) and Atlantic halibut (Hippoglossus hippoglossus). Fish Physiol. Biochem. 36, 719-730.

Zottoli, S. J.; Burton, O. T.; Chambers, J. A.; Eseh, R.; Gutierrez, L. M.; Kron, M. M., 2003: Transient use of tricaine to remove the telencephalon has no residual effects on physiological recordings of supramedullary/dorsal neurons of the cunner, Tautogolabrus adspersus. Biol. Bull. 205, 211-212.

Zydlewski, G. B.; Gale, W.; Holmes, J.; Johnson, J.; Brigham, T. Thorson, W., 2008: Use of electroshock for euthanizing and immobilizing adult spring Chinook salmon in a hatchery. N. Am. J. Aquacult. 70, 415-424.

Author's address: Natalija Topic Popovic, Laboratory for Ichthyopathology - Biological Materials, Division for Materials Chemistry, Rudjer Boskovic Institute, CR-Zagreb 10 002, Croatia E-mail: ntopic@irb.hr 